\title{
Relevância das informações geradas pelo Siscustos para a nova administração pública, na percepção dos analistas e auditores das ICFEx
}

Relevance of information generated by Siscustos for the new public management, on perception of analysts and auditors of ICFEx

Relevancia de la información generada por Siscustos para la nueva gestión pública en la percepción de los analistas y auditores de ICFEx

\section{Tarso Rocha Lula Pereira}

Mestre pelo Programa Multiinstitucional e Inter-regional de Pós-Graduação em Ciências Contábeis - UnB/UFPB/UFRN

Professor de Ciências Contábeis do UNIFACEX

Endereço: Av. Ayrton Senna, n॰ 880, Casa 210, Nova Parnamirim

CEP 59.153-150 - Parnamirim/RN - Brasil

E-mail: tarso.rocha@ig.com.br

Telefone: +55 (84) 99901-4770

\section{Aneide Oliveira Araujo}

Pós-doutora pela Faculdade de Economia da Universidade do Porto

Professora do Departamento de Ciências Contábeis da Universidade Federal do Rio Grande do Norte e do Programa Multiinstitucional e Inter-regional de Pós-Graduação em Ciências Contábeis - UnB/UFPB/UFRN

Endereço: Rua Prof ${ }^{\mathrm{a}}$ Dirce Coutinho, 1890. Apt $^{\circ} 1801$ - Capim Macio

CEP 59.082-180 - Natal/RN - Brasil

E-mail: aneide@ufrnet.br

Telefone: + 55 (84) 99974-6137

Artigo recebido em 11/12/2015. Revisado por pares em 23/05/2016. Reformulado em 02/06/2016. Recomendado para publicação em 06/06/2016 por Sandra Rolim Ensslin (Editora Científica). Publicado em 14/06/2016. 


\title{
Resumo
}

O Sistema de Custos Gerencial (SISCUSTOS) é utilizado pelo Exército Brasileiro para registro e análise dos custos. Este estudo teve como objetivo verificar se o SISCUSTOS gera informações relevantes sobre a apuração de custos, na percepção dos Auditores e Analistas das Inspetorias de Contabilidade e Finanças do Exército (ICFEx). A amostra da pesquisa foi formada por 88 profissionais de contabilidade que analisam o sistema do Exército Brasileiro. $\mathrm{Na}$ metodologia, a pesquisa consistiu em um estudo de caso de natureza descritiva, utilizando métodos qualitativos e quantitativos. A pesquisa teve como principal achado que, para Analistas e Auditores das ICFEx, 45,83\% concordam totalmente que a legislação alterou a forma de trabalho em relação às informações geradas. Assim, pode-se considerar que, na percepção dos Analistas e Auditores das ICFEx, há o uso da contabilidade de custos, e que o SISCUSTOS se adéqua ao que foi proposto pelas normas de contabilidade pública.

Palavras-chave: Administração pública. Custos. Exército brasileiro. Siscustos. Tomada de decisão

\begin{abstract}
The System of Managerial Costs (SICUSTOS in Portuguese acronym) is used by Brazilian Army to report and analysis of costs. This study had as aim to verify whether the SICUSTOS generates relevant information on the cost inspection according to the perception of managers from the Army Finance and Accountancy Inspector (ICFEx). The sample of the research is featured by 88 accountancy professionals who analyze the Brazilian Army system. The methodology consisted of a descriptive case study using both qualitative and quantitative methods. The main finding of the research were that in the ICFEx, $45,83 \%$ totally agree that the legislation has changed the way of work related to the generated information. Then, it is possible consider, in the perception of ICFEx, there is a costs accountancy in use and SISCUSTOS is adequate to what was proposed by public accountancy rules.
\end{abstract}

Key words: Public management. Costs. Brazilian army. Siscustos. Decision making.

\section{Resumen}

El Sistema de Gestión de Costos (SISCUSTOS en su acrónimo en portugués) es utilizado por el Ejército Brasileño para el registro y análisis de los costos. Este estudio tuvo como objetivo verificar si el sistema SISCUSTOS genera información pertinente sobre los costos, en la percepción de Auditores y Analistas de las Inspectorías de Contabilidad y Finanzas del Ejército (ICFEx). La muestra de la investigación fue compuesta por 88 profesionales de contabilidad que analizan el sistema de Ejército Brasileño. En la metodología, la investigación consistió en un estudio de caso de carácter descriptivo, utilizando métodos cualitativos y cuantitativos. La investigación tuvo como principal resultado que, para los Analistas y Auditores de ICFEx, 45,83\% están de acuerdo que la legislación ha cambiado la forma de trabajar con la información generada. Por lo tanto, se puede considerar que la percepción de los Analistas y Auditores de ICFEx hay el uso de la contabilidad de costos, y el SISCUSTOS se adapta a lo que fue propuesto por las normas de contabilidad pública.

Palabras clave: Administración pública. Costos. Ejército de Brasil. Siscustos. Toma de decisiones. 


\section{Introdução}

No Brasil, os gestores públicos estão passando por diversas atualizações. Trata-se de ajustes que buscam melhor utilização dos recursos públicos, colocados à sua disposição a fim de alcançar melhores resultados, atingindo a eficiência, a economicidade e a eficácia necessárias à gestão, sendo considerado o desempenho que, consequentemente, beneficiará a sociedade.

Passos (2012) afirma que as novas Normas Brasileiras de Contabilidade Aplicadas ao Setor Público (NBC TSP) vão acrescentar mais velocidade no fluxo de informações e transparência no uso do patrimônio público. Por sua vez, Faria (2010) aborda um novo enfoque, chamado de Nova Administração Pública, New Public Management (NPM), que privilegia uma visão mais econômica e gerencial para a administração pública.

Dessa forma, percebe-se que os administradores atribuem total importância à implantação de um sistema de controle de custos no setor público, o que aumentará a capacidade gerencial e facilitará a verificação da eficiência e o desempenho obtidos na alocação dos recursos, na consecução de um produto ou de um serviço.

A necessidade de apuração, mensuração e controle de custos tem sido prevista na legislação brasileira desde 1964, quando da publicação da Lei 4.320, de 17 de março de 1964, como posteriormente, com a publicação do Decreto-Lei $n^{\circ}$ 200, de 25 de fevereiro de 1967 , que implementou a Reforma Administrativa.

A administração pública tem a responsabilidade de implementar e manter um sistema de custos para que seja possível avaliar e acompanhar as gestões orçamentária, financeira e patrimonial. Com o mandamento legal introduzido pela Lei de Responsabilidade Fiscal (LRF), Lei Complementar $n^{\circ} 101$, começaram a surgir mais estudos sobre a contabilidade de custos aplicada ao setor público. No entanto, os procedimentos peculiares da contabilidade governamental, os quais se baseiam nos enfoques legalista e orçamentário, na observância do regime contábil misto relativo à receita pública (regime de caixa) e à despesa pública (regime de competência), não permitem uma efetiva gestão de custos utilizando a contabilidade governamental contemporânea como fonte primária.

Partindo desse cenário, o Exército Brasileiro (EB), em sintonia com a crescente tendência de imprimir, ao setor público, os princípios gerenciais de eficiência, efetividade e avaliação de desempenho, resolveu implantar o Sistema de Custos Gerencial (SISCUSTOS) em todas as suas Organizações Militares (OM).

Verifica-se que as Normas Brasileiras de Contabilidade Aplicadas ao Setor Público vão acrescentar, à contabilidade aplicada na Administração Pública Federal, mais velocidade no fluxo de informações e transparência no uso do patrimônio público (PASSOS, 2012).

Uma pesquisa em um órgão militar concluiu que o SISCUSTOS, em fase inicial de implantação, já permite a medição dos custos e a avaliação de desempenho, mas que ainda há a necessidade de acompanhamento até a total implantação (LUZ; REIS, 2008).

O estudo verifica o estágio da apuração de custos na Administração Pública, mais especificamente no Exército Brasileiro, e se essas informações são base para a tomada de decisão dos Analistas e Auditores das Inspetorias de Contabilidade e Finanças do Exército (ICFEx). 
Diante do exposto, a questão que se apresenta e que direciona a pesquisa é: qual a percepção dos Auditores e Analistas das ICFEx a respeito da relevância das informações geradas pelo SISCUSTOS, em face da nova contabilidade pública para o processo decisório?

O objetivo desta pesquisa é verificar qual a relevância das informações geradas pelo SISCUSTOS, em face da nova contabilidade pública para o processo decisório, na percepção dos Auditores e Analistas das ICFEx.

O presente estudo justifica-se, inicialmente, por haver poucas pesquisas na área, entre as quais algumas estão apresentadas na revisão da literatura, demonstrando seu estágio. Apresenta-se que os atuais estudos na área encontram-se em uma situação intermediária, pois o sistema ainda está sendo empregado e, desta forma, é apresentado o estágio do assunto e quanto ele avançou.

Assim, surgiu o interesse em investigar qual a percepção dos Analistas e Auditores das Inspetorias de Contabilidade sobre as informações que são geradas pelo Sistema de Custos do Exército Brasileiro.

O estudo da ferramenta gerencial desenvolvida pelo Exército Brasileiro pode ser um instrumento para a melhoria do desempenho organizacional, o qual possibilitará obter subsídios para o planejamento das atividades e para a tomada de decisões, e que podem ser aplicadas para outros órgãos públicos.

Desta forma vai possibilitar que outros órgãos públicos percebam o estágio alcançado pelo Exército Brasileiro, e possam aplicar estas percepções no desenvolvimento de seus Sistemas de Custos.

Para situar o leitor na compreensão deste estudo apresenta-se, de forma resumida, a organização do trabalho. Ele se estrutura em cinco seções, incluindo esta introdução em que se apresentam a contextualização do problema de pesquisa, seus objetivos e a justificativa. A seguinte, Revisão da Literatura, focaliza teorias relacionadas ao contexto da contabilidade aplicada ao setor público e seus reflexos no sistema de custos. Na terceira, Aspectos Metodológicos, explicitam-se os procedimentos que auxiliaram na coleta e no tratamento dos dados relativos às organizações investigadas. Na quarta, a Análise dos Resultados descreve as percepções das unidades estudadas. Nas considerações finais apresentam-se as conclusões deste estudo e as recomendações para estudos futuros nesta temática. Em seguida, apresentam-se as referências utilizadas nesta pesquisa.

\section{Referencial Teórico}

Esta seção apresenta uma revisão da literatura que trata da Administração Pública, da Nova Administração Pública, da Informação Contábil, da Contabilidade de Custos na Administração Pública e do SISCUSTOS.

\subsection{Administração pública}

Todos os entes públicos, sejam eles de nível federal, estadual ou municipal, devem objetivar satisfazer as necessidades coletivas, criando, realizando e expandindo os serviços públicos executados pela administração pública (DE FARIA, 2012). 
A administração pública, percebida como a estrutura do Poder Executivo, pode ser entendida como todo o sistema de governo, compreendendo um conjunto de ideias, atitudes, normas, processos, instituições que determinam a forma de exercer a autoridade política e de atender aos interesses públicos (MATIAS-PEREIRA, 2006).

Para De Faria (2012), a administração pública é a atividade em que os gestores públicos procuram satisfazer as necessidades da sociedade. E, assim, verificam as necessidades e os anseios da sociedade, atendendo-a mediante a prestação de serviços públicos, também com a disponibilização de informações, que poderão ser utilizadas nas decisões que visem a aproveitar melhor os recursos públicos disponíveis, o que poderá ter, como consequências, a continuidade, a melhoria e a expansão das ações governamentais.

Para Costa (2008), a administração pública deveria se guiar pelos princípios do planejamento, da coordenação, da descentralização, da delegação de competência e do controle.

Desta forma, percebe-se que a estrutura pública está dividida para atender aos municípios, estados, Distrito Federal e país como um todo, com a intenção de prestar serviços necessários à população.

\subsection{Nova Administração Pública}

Conforme Mello (2006), o processo de mudança da administração de negócios para a administração pública é conhecido como New Public Management (NPM) ou Nova Gestão Pública (NGP), com a característica de enfatizar a maneira como o setor privado pratica a gestão.

A NPM, incentivada pelo aumento das expectativas e das demandas dos cidadãos em uma parcela significativa dos países (Inglaterra, Estados Unidos, Austrália, Nova Zelândia, e Brasil inclusive), passou a exigir uma nova forma de orientação na prestação de serviços por parte da Administração Pública para responder à exigência da população (MATIASPEREIRA, 2006).

A primeira reforma de maior vulto na administração pública foi na década de 1930 , em que o Estado passou da administração patrimonialista para a burocrática, voltada basicamente à burguesia industrial na liderança, e ao avanço dos processos industriais ou desenvolvimento econômico (BRESSER PEREIRA, 2007).

De acordo com Slomski, Camargo e Amaral Filho (2008) tem-se, no Brasil, uma administração pública gerencial que dá ênfase ao cidadão e aos resultados, com exigência do gestor público em eficiência, transparência e, principalmente, em qualidade na prestação dos serviços públicos e no exercício das funções estatais.

Essas transformações corriam em um contexto de globalização e difusão da Tecnologia da Informação que, por sua vez, refletiam profundamente no ambiente de negócios, exigindo, das organizações, mais flexibilidades nas suas operações.

Além desses aspectos, o Brasil, nas décadas de 1980 e 1990, através de reformas, fez com que as pessoas percebessem que uma das razões da crise fiscal pela qual passava o Estado era motivada, também, pela ineficiência estrutural da administração pública burocrática. Os serviços prestados pelo Estado para o cidadão precisavam ser realizados de forma efetiva e eficiente para poder cumprir seu objetivo, que é visar ao bem comum.

Essas reformas, que ocorreram mundialmente, responderam à globalização em andamento, reduzindo a autonomia dos Estados, e começa a se desenvolver em quase todo o 
mundo nos anos 1970, e expandiu-se nos anos 1980. No Brasil, a reforma do Estado começou em meio a uma grande crise econômica, que chegou ao seu auge em 1990, com a hiperinflação.

Ao colocar em prática essas reformas, a área pública aproxima sua forma de atuação à da área privada. Bennett e Krebs (1991) argumentam que a intenção era tornar o setor público mais parecido com o setor privado, permitindo, assim, que os dois setores trabalhassem de forma mais próxima.

Então, práticas foram sendo transferidas de um setor para o outro. Conforme Hodges et al. (1996), a transferência de governança corporativa para o setor público ocorreu em tal medida, que esse setor pode ter substituído a responsabilidade pública.

A maior contribuição da reforma administrativa está voltada à governança, entendida como o aumento da capacidade de governo, através da adoção dos princípios da administração de uma forma mais gerencial.

Estes princípios passam pela orientação da ação do Estado para o cidadão, pela ênfase no controle de resultados através dos contratos de gestão, pelo fortalecimento e autonomia da burocracia, pela separação entre as secretarias formuladoras de políticas e as unidades executoras, e pela adoção cumulativa de três formas de controle sobre as unidades executoras de políticas públicas (BRESSER PEREIRA, 1997).

A utilização de técnicas de trabalho de um e outro setor constitui-se, então, um tópico importante a ser pesquisado. Hyndman e McDonnell (2009), pesquisadores de contabilidade interessados em acrescentar conhecimento de prestação de contas e de governança corporativa, pesquisaram sobre a interface entre os setores público e privado.

Passos (2012) diagnosticou, entre outros aspectos, que as novas Normas Brasileiras de Contabilidade Aplicadas ao Setor Público vão acrescentar, à contabilidade aplicada na Administração Pública Federal, mais velocidade no fluxo de informações e transparência no uso do patrimônio público.

A pesquisa de De Faria (2012) aponta a nova administração pública, estimulando os servidores públicos a assumirem compromisso, atendendo às demandas da sociedade, revendo a prestação dos serviços ao público, e buscando maior efetividade e eficiência.

Deve-se considerar, também, o Plano de Implantação de Procedimentos Contábeis Patrimoniais (PIPCP), que define prazos-limites para a consolidação das contas públicas e validação de dados no Sistema de Informações Contábeis e Fiscais do Setor Público Brasileiro (Siconfi). Assim foi definido pela Secretaria do Tesouro Nacional (STN), através da Portaria 548 , de 24 de setembro de 2015. O PIPCP considerou a implantação de forma gradual, tendo em vista que implantar de forma abrupta mostrou-se inviável, com base em experiências dos entes da Federação sobre dificuldades operacionais e de recursos materiais e humanos.

Os prazos para aplicação das novas normas foram estipulados considerando os entes da federação, como União, Distrito Federal e Estados, e municípios com mais e menos de 50.000 habitantes, contando que algumas alterações só serão verificadas em 2022, o que pode demonstrar a concepção, pela STN, da necessidade de um período que dê condições da adequabilidade de sistemas e dos agentes da administração às novas regras.

Dessa forma, a New Public Management influenciou as mudanças no setor público e, consequentemente, nas informações contábeis a serem prestadas. 


\subsection{Informação Contábil}

O objetivo da Contabilidade é fornecer informações para que seus interessados possam usá-las como subsídio no processo de tomada de decisões, sendo reportadas aos seus usuários através dos relatórios contábeis (KOTHARI, 2001). Para Souza (2004), a Contabilidade objetiva produzir informações que sejam relevantes aos seus usuários, servindo de base para a tomada de decisão econômico-financeira, de acordo com seu julgamento.

A utilidade da informação contábil vai depender de sua qualidade na produção e transmissão, uma vez que o meio de comunicação mais frequente com o qual a empresa se relaciona com seus usuários são as demonstrações contábeis; ou seja, será através destas que o gestor irá direcionar sua atenção, no sentido de tomar a decisão mais adequada (CUNHA; SILVA, 2009). Conforme Coelho e Lins (2010), a informação contábil será considerada de qualidade e atingirá seu objetivo de auxiliar na tomada de decisão se seguir pressupostos, normas e regras que permitam sua compreensão, comparação e análise crítica, para que possa servir de apoio a uma decisão com maiores chances de acerto.

De acordo com o CPC - Comitê de Pronunciamentos Contábeis (2011, p. 17), ao discorrer sobre a estrutura conceitual para elaboração e divulgação de relatório contábilfinanceiro, a informação contábil-financeira relevante "é aquela capaz de fazer diferença nas decisões que possam ser tomadas pelos usuários".

Este pensamento é compartilhado por muitos pesquisadores, como Kothari (2001), que apresentou e discutiu, de forma ampla, essa tendência em seu trabalho. Sua pesquisa foi desenvolvida analisando a relação entre o lucro (e outras informações contábeis), informações não contábeis e o resultado.

Com isso, torna-se importante pesquisar a percepção dos operadores da contabilidade quanto à relevância das mudanças introduzidas pela adoção das normas brasileiras de contabilidade aplicadas ao setor público.

Xavier Júnior (2011) foi um dos pesquisadores que abordaram o tema sobre a informação contábil resultante das mudanças introduzidas pela adoção das Normas Brasileiras de Contabilidade aplicadas ao setor público. Conforme este autor, as novas alterações das normas no setor público serão capazes de melhorar a informação contábil, tornando-a mais útil e auxiliando na tomada de decisão.

O estudo de Passos (2012), por sua vez, teve por objetivo oferecer um breve diagnóstico do impacto das Normas Brasileiras de Contabilidade Aplicadas ao Setor Público, o cenário e as perspectivas que estas poderão trazer no norteamento das atividades contábeis que são executadas na Administração Pública Federal.

Assim, conclui-se que a atualização das normas de contabilidade aplicadas ao setor público tende a gerar melhor informação contábil.

\subsection{Contabilidade de Custos na Administração Pública}

O Study 12, elaborado pelo International Federation of Accountants (IFAC), que tratou das possibilidades de utilização de custo na Administração Pública, revelou que a gestão pública tende a ser favorecida em relação à eficiência e à efetividade das atividades promovidas pelo Estado com a implementação sistemática da utilização da contabilidade de custos. 
Para Slomski (2005), a utilização da contabilidade de custos e sua apuração são assuntos recentes, que ganharam força após a adoção da LRF, chamando a atenção de profissionais de contabilidade, de pesquisadores e de gestores públicos.

Para Machado (2012), a informação de custos na gestão pública provê informações que podem auxiliar na tomada de decisão, e também podem servir de controle e avaliação da eficiência e da efetividade.

Machado e Holanda (2010) afirmam que o sistema de custos proporciona, aos gestores, a comparação de órgãos com atividades semelhantes, com o objetivo de melhorias no desempenho dos administradores públicos.

Ainda que se reafirme a necessidade de registro dos custos pela contabilidade, tais dispositivos trouxeram somente a obrigatoriedade de apuração aos custos industriais, não abrangendo toda a administração pública. Este fato que foi corrigido com a publicação do Decreto-Lei $\mathrm{n}^{\circ} 200$ (BRASIL, 1967), que implementou a Reforma Administrativa, apresentando, em seu art. 79, que a contabilidade deverá apurar os custos dos serviços de forma a evidenciar os resultados da gestão.

Diniz (2004) afirma que um modelo de administração pública gerencial necessita de sistemas de informações gerenciais compatíveis com as necessidades dos gestores para terem sustentação dos seus processos decisórios.

Com a determinação da LRF, a aplicabilidade, na administração pública federal, de dois atos administrativos impulsionou os estudos e discussões sobre o tema. Primeiramente, o pronunciamento do Tribunal de Contas da União (TCU), formalizado pelo Acórdão $\mathrm{n}^{\circ}$ 1078/2004-TCU, que definiu administração pública federal, faltando apenas a definição de prazo e a implantação de sistemas de custos. Posteriormente, houve a criação da Comissão Interministerial de Custos, pela Portaria Interministerial $n^{0}$ 945, de 26 de outubro de 2005, do Ministério da Fazenda e do Ministério do Planejamento, Orçamento e Gestão, com objetivo de elaborar estudos e propor diretrizes, métodos e procedimentos para subsidiar a implantação de Sistemas de Custos na Administração Pública Federal.

Os sistemas devem contemplar medidas de resultados e de custo. Para que mecanismos possam ser utilizados na obtenção de informações gerenciais, considera-se fundamentalmente a existência de um sistema de custeamento (DINIZ, 2004).

Alguns autores apresentaram, em suas pesquisas, quais informações de custos serão relevantes para a administração pública. Para Gibbon et al. (2008), por exemplo, deve-se prover informações que auxiliem a tomada de decisão do gestor público, como resultados baseados em sistemas de custeio específicos aos órgãos públicos.

Em orientação, a Secretaria de Orçamento Federal (SOF) (2008) define que benefícios propiciados pelas informações de custo devem superar os custos necessários para obtê-las, sendo estas relevantes e úteis ao processo decisório.

Faria (2010) afirma que há peculiaridades que não devem influenciar no patrimônio, sendo fundamental que os gestores públicos reconheçam e entendam os procedimentos para registro dessas peculiaridades, pois, ao estruturar um sistema de custos aplicado ao setor público, tais particularidades devem ser ajustadas.

Sobre práticas de gestão implantadas em outro país, Klages e Löffer (1998) apresentaram que, na Alemanha, a mensuração dos custos proporcionou maior transparência nos gastos públicos. Naquele país, as metas e os resultados das ações governamentais eram 
facilmente identificados, permitindo a inserção do cidadão como controlador das políticas locais.

No Brasil, em 2011 a NBC T 16.11, que trata do Sistema de Informação de Custos do Setor Público, foi aprovada pelo Conselho Federal de Contabilidade (CFC). Esta norma estabelece a conceituação, o objeto, os objetivos e as regras básicas para mensuração e evidenciação dos custos no setor público e ainda apresenta, o Subsistema de Informação de Custos do Setor Público (SICSP).

O SICSP poderá proporcionar melhor registro, processo e evidenciação dos custos de bens e serviços e outros objetos de custos produzidos e oferecidos à sociedade pela entidade pública. O objetivo é facilitar a mensuração, registro e evidenciação dos custos dos produtos, serviços, programas, projetos, atividades, ações, órgãos e outros objetos de custos da entidade, apoiando a avaliação de resultados e desempenhos, permitindo a comparação entre os custos da entidade com os custos de outras entidades públicas.

Desta forma, poderá estimular a melhoria do desempenho dessas entidades, o que poderá apoiar a tomada de decisão em processos, tais como comprar ou alugar, produzir internamente ou terceirizar determinado bem ou serviço, apoiando as funções de planejamento e orçamento, fornecendo informações que permitam projeções mais aderentes à realidade, com base em custos incorridos e projetados, para apoiar programas de controle de custos e de melhoria da qualidade do gasto.

Assim, tratando também da implantação de um sistema de custos, a STN publicou e

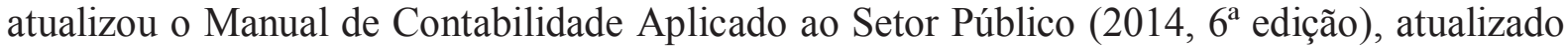
pela $6^{a}$ edição do Manual, aprovado pela portaria do STN n 700 de 2014. Além disso, a International Federation of Accountants (IFAC), por meio do IFAC Public Sector Committee - Study 12 (2000), apresentou um conjunto de diretrizes que orientam o processo de implementação da contabilidade de custos no setor público.

O estudo de Oliveira, Silva e Nascimento (2013) mostra que, há pouco tempo, a questão dos custos na esfera pública ganhou força, após o processo de adequação da contabilidade brasileira aos padrões internacionais. Essa questão surgiu com a Lei $\mathrm{n}^{0} 11.638$, de 28 de dezembro de 2007, com aplicabilidade para a área privada, incentivando normativos para órgãos públicos.

Faria (2010) demonstra que a contabilidade governamental não reconhecia obrigações no momento do fato gerador, por não haver autorização legislativa, o que descumpria o Princípio da Competência, e deixava de lado alguns eventos de natureza econômica.

Assim, a Contabilidade Aplicada ao Setor Público obedece aos Princípios de Contabilidade, no caso, o Princípio da Competência, tanto para o reconhecimento da receita quanto para a despesa, tendo em vista que o artigo 35 da Lei $\mathrm{n}^{\circ} 4.320 / 64$ define que pertencem ao exercício financeiro as receitas nele arrecadadas e as despesas nele legalmente empenhadas.

\subsection{Sistema de Custos Gerencial (SISCUSTOS) do Exército Brasileiro}

Conforme Meneses Júnior (2013), a obtenção de eficiência no gasto público depende de se ter o conhecimento dos custos necessários para a oferta de bens ou serviços, o que permitiria avaliar se resultados da ação governamental justificam os esforços empreendidos, e se há possibilidade de redução de custos sem diminuir a qualidade. 
O Exército Brasileiro (EB), em sintonia com os princípios gerenciais da eficiência, da efetividade e da avaliação de desempenho, e com a crescente tendência de aplicação destes no setor público, buscou amparar-se na Reforma do Aparelho do Estado de 1995, na LRF e na Portaria $n^{\circ}$ 932, de 19 de dezembro de 2007, do Comandante do Exército (Cmt Ex).

Após trabalho realizado pela Diretoria de Contabilidade (D Cont) com o apoio técnico de suas Inspetorias de Contabilidade e Finanças, entre elas a $10^{\mathrm{a}}$ ICFEx, o EB concluiu, ao final do exercício financeiro de 2008, a implantação do Sistema Gerencial de Custos (SISCUSTOS) em todas as suas Organizações Militares (OM).

Antes disso, já existiam pesquisas que demonstravam a importância da apuração dos custos na área pública, como a de Diniz (2004), que apresentou a necessidade da avaliação e do acompanhamento da gestão através de um sistema de custos.

Passos (2012) abordou o Sistema Gerencial de Custos do Exército Brasileiro, fruto da NBC T 16.5 - Registro Contábil. Este fato coloca a Força Terrestre na vanguarda dos órgãos públicos na utilização de tal sistema para fins de controle gerencial, e de sua integração com o Sistema Integrado de Administração Financeira do Governo Federal (SIAFI) e outros sistemas da tecnologia da informação.

A Portaria $n^{\circ} 932$ do Cmt do Ex, de 19 de dezembro de 2007, dispõe sobre a aprovação das normas para o funcionamento do SISCUSTOS que, em seu inciso IV, art. 13, prevê a competência das OM em manter atualizados os dados relativos ao SISCUSTOS sob sua responsabilidade. Assim, em consonância com a legislação supracitada, direcionam e embasam o sistema de custos.

Luz e Reis (2008) analisaram se o método de custeio, em fase de implantação pelo Exército, é adequado para mensurar os custos logísticos em um Batalhão de Suprimento, dentro do conceito da administração gerencial com foco nos resultados. Também relataram a importância da apuração de custos na Administração Pública gerencial, descrevendo os principais métodos de custeio, e apresentaram o sistema gerencial de custos do Exército.

Pode-se perceber que o Exército Brasileiro está buscando atualizar-se e colocar em prática o previsto nas novas normas de contabilidade aplicadas ao setor público, em relação à apuração dos seus custos.

\section{Procedimentos Metodológicos}

As decisões no mercado de trabalho têm se fundamentado, cada dia mais, em informações do campo científico, e aqueles que não podem compreender como são coletados e organizados os fatos, não serão capazes de separar fatos de pura especulação (ALMEIDA et al., 2009).

No desenvolvimento foi utilizado o método indutivo que, segundo Lakatos e Marconi (2010), é um processo mental em que, partindo de dados particulares, infere-se uma verdade geral ou universal.

Quanto aos objetivos, este trabalho é uma pesquisa descritiva, pois se pretende descrever características de determinada população ou fenômeno, estabelecendo as relações entre as variáveis (GIL, 2008).

Quanto aos meios, este artigo classifica-se como bibliográfico e levantamento, pois foram desenvolvidas pesquisas, e também foram aplicados questionários aos servidores das 
ICFEx de todo o Brasil, podendo, ainda, classificar-se como um estudo de caso, pois, conforme Gil (2008), o estudo de um ou poucos objetos permite um conhecimento amplo e detalhado sobre eles, o que estabelece base para futuras investigações, podendo ser aplicado a um ambiente, um sujeito ou uma situação em particular, restringindo-se a um grupo.

Raupp e Beuren (2006, p. 85) discorrem que os "dados referentes a esse tipo de pesquisa podem ser coletados com base em uma amostra retirada de determinada população ou universo que se deseja conhecer".

A pesquisa realizada para este artigo consistiu em um estudo de caso, utilizando métodos qualitativos e quantitativos.

Utilizaram-se as variáveis determinadas pelo estudo de Diniz (2004), que apresentou as percepções dos assessores contábeis. Foi questionado se, em relação aos aspectos conceituais de custo e resultado na administração pública, eles estão de acordo com os fundamentos conceituais dispostos na literatura e na legislação.

Xavier Júnior (2011), em sua pesquisa, apontou que as informações contábeis produzidas foram consideradas muito úteis por apenas $29,1 \%$, e por $39,3 \%$ as informações foram consideradas sem utilidade. A partir dessas variáveis adaptou-se ao órgão federal em questão, e após a aplicação de pré-testes, houve a aplicação do questionário, como instrumento de coleta, de forma específica às unidades do Exército Brasileiro.

O objeto de estudo na presente pesquisa é o Exército Brasileiro. Procurando responder à questão de pesquisa, o questionário foi aplicado em um grupo constituído por 11 (onze) Inspetorias de Contabilidade e Finanças do Exército (ICFEx) dispostas em todas as regiões do Brasil, que analisam, elaboram e apresentam as informações contábeis para serem aprovadas pelo Tribunal de Contas da União.

As ICFEx são setoriais de contabilidade e de controle que, conforme estabelecido pela Portaria $n^{\circ} 050$, de 10 de fevereiro de 2003, têm como finalidade organizar as atividades de controle interno, de forma a criar condições para avaliar a adequação dos controles, a eficiência e a eficácia da gestão (SEF, Portaria ${ }^{\circ} 050,10$ de fevereiro de 1964).

De acordo com a Portaria $\mathrm{n}^{\circ}$ 015, de 16 de janeiro de 2004, as unidades de controle interno do Exército Brasileiro, as ICFEx, são distribuídas em todas as regiões do Brasil, auditando, analisando e controlando todas unidades gestoras do Exército.

As funções que foram consideradas como respondentes são aquelas em que o Analista e o Auditor verificam as informações sobre SISCUSTOS das unidades militares.

Cada Inspetoria possui, em média, 4 Analistas e 4 Auditores, que responderam ao questionário. Isso proporcionou um alcance a 88 respondentes em todo o território brasileiro, abrangendo as sedes no Rio de Janeiro, em São Paulo, Curitiba, Juiz de Fora, Porto Alegre, Belém, Recife, Manaus, Campo Grande, Fortaleza e Brasília.

Os dados foram obtidos por meio de questionário enviado via Correios, já impressos, e o preenchimento e devolução tiveram acompanhamento, via e-mail, às 11 unidades da ICFEx existentes no Brasil, durante o mês de agosto de 2014. Além desse envio, houve contato com os comandantes e chefes das organizações militares para confirmar o recebimento e solicitar o preenchimento pelos servidores, tendo em vista a necessidade de autorização do instrumento.

O questionário foi estruturado para permitir uma graduação das respostas, de forma escalar, com cinco pontos tipo Likert: concordo totalmente, mais concordo do que discordo, mais discordo do que concordo, discordo totalmente, e desconheço o assunto.

As questões foram direcionadas a responder sobre a área de custos, e para verificar possíveis acertos que poderiam ser realizados na adaptação do questionário. 
Ocorreu a realização de um pré-teste, com a intenção de verificar a aderência ao problema pesquisado, bem como a coerência do instrumento utilizado. Este confirmou a manutenção e a forma de aplicação do questionário pré-testado.

Utilizaram-se questões como base da montagem do pré-teste, que foram:

1. A nova legislação da área pública alterou a forma de trabalho em relação às informações que são geradas no Exército.

2. As informações que são produzidas atualmente pela contabilidade apoiam o processo de decisão das ICFEx.

3. A contabilidade de custos aplicada no Exército está alinhada com as novas normas contábeis.

4. Os dados que são lançados no SISCUSTOS estão de acordo com as novas normas em relação à contabilidade de custos.

5. As informações geradas pelo SISCUSTOS são úteis no processo de tomada de decisão.

6. O sistema de custos torna possíveis as comparações e cria medidas e padrões de grande utilidade para a tomada de decisão.

7. A existência do SISCUSTOS permite o controle dos desperdícios de recursos públicos.

8. O SISCUSTOS permite comparar os custos com os de outra unidade no Exército que possui as mesmas peculiaridades.

9. O SISCUSTOS proporciona a obtenção de informações capazes de analisar o desempenho do órgão que o utiliza.

10. O conhecimento dos custos dos produtos e serviços públicos é útil para decidir por sua continuidade ou não.

Assim, um primeiro questionário, pré-teste, foi aplicado com os servidores que alimentam o SISCUSTOS com os dados referentes aos custos. As unidades analisadas foram as sediadas em Natal-RN, que são 06 (seis), nas quais verificou-se a percepção daqueles que geram as informações.

Tendo em vista a melhoria e o aprimoramento do questionário, o pré-teste pode ser aplicado mais de uma vez (LAKATOS; MARCONI, 2010). O que foi considerado e aplicado confirmou a primeira constatação, de que as questões eram adequadas.

Segundo Lakatos e Marconi (2010), depois de redigido o questionário, faz-se necessário que este seja testado com alguns participantes de uma população escolhida, a fim de que sejam verificadas falhas e, caso seja necessário, seja reformulado o instrumento de coleta após o pré-teste.

Neste primeiro pré-teste obteve-se que o questionário possuía aderência ao problema pesquisado, também a coerência do instrumento utilizado.

Buscando aprofundar o tema pesquisado, realizou-se um segundo pré-teste, e foi aplicado em um Auditor da ICFEx, profissional que verifica as informações enviadas pelas Organizações Militares e tomam as decisões com base nas informações geradas pelo SISCUSTOS. O respondente do novo pré-teste não participou do questionário propriamente dito. $\mathrm{Na}$ aplicação desse segundo pré-teste, revelou-se que as questões possuíam aderência ao problema pesquisado, bem como a coerência do instrumento utilizado. 
Visando a alcançar os objetivos traçados nesta pesquisa, embasada em um questionário testado previamente, foi feito um estudo de caso nas Inspetorias de Contabilidade e Finanças do Exército, verificando se o SISCUSTOS se adéqua ao que foi proposto pelas normas de contabilidade pública, e se fornece subsídios à tomada de decisão.

Os itens dos questionários foram tabulados utilizando planilhas eletrônicas, obtendo, assim, os cruzamentos entre as variáveis de interesse para análise, que foram apresentadas através de tabelas com a frequência das respostas e a média percentual.

A estatística descritiva pode apresentar e analisar dados de natureza quantitativa e, às vezes, descrevem-se variáveis isoladamente, outras vezes caracterizam-se as associações que relacionam uma variável a outra (BABBIE, 2003).

$\mathrm{Na}$ abordagem quantitativa utilizou-se o Alfa de Cronbach pelo método das variâncias. O valor mínimo aceitável para o alfa é 0,70 . Abaixo deste valor. A consistência interna da escala utilizada é considerada baixa (STREINER, 2003).

Esse método é utilizado para sinalizar a confiabilidade dos dados produzidos pelos questionários, e como forma de estimar a confiabilidade em uma pesquisa, pois mede a correlação entre respostas por intermédio da análise das respostas dadas pelos respondentes, apresentando uma correlação média entre as perguntas. O coeficiente $\alpha$ é calculado a partir da variância dos itens individuais, e da variância da soma dos itens de cada avaliador, de todos os itens de um questionário que utilizem a mesma escala de medição (ALMEIDA; SANTOS; COSTA, 2010).

A verificação da fidedignidade do questionário pode ser medida com a utilização do software Spss, na sua versão 20.0 .

O Alfa de Cronbach calculado para o questionário deste estudo corresponde a 0,985, revelando boa consistência interna do instrumento de pesquisa. Assim, com base no alfa, este questionário consegue medir o grau de concordância em relação ao que foi questionado nas ICFEx.

\section{Análise dos Resultados}

\subsection{Auditores e Analistas Pesquisados}

Nesta seção são expostos os resultados referentes aos Auditores e Analistas participantes da pesquisa.

Em relação ao tempo de serviço, apenas $25 \%$ possui de 1 a 10 anos, e o restante apresenta mais de 10 anos de experiência. Este dado revela um tempo de serviço menor do que o verificado nos militares das OM.

Tabela 1 - Características sociodemográficas

\begin{tabular}{|c|c|c|c|}
\hline & \multirow[t]{2}{*}{$n$} & \multirow[t]{2}{*}{$\%$} \\
\hline & \multirow{2}{*}{$\begin{array}{l}\text { Características } \\
\text { Sexo } \\
\begin{array}{l}\text { Masculino } \\
\text { Feminino }\end{array}\end{array}$} & & \\
\hline & & & \\
\hline
\end{tabular}

$\begin{array}{lrr}\text { De } 18 \text { a } 22 \text { anos } & 2 & 4,2 \\ \text { De } 23 \text { a } 27 \text { anos } & 5 & 10,4 \\ \text { De 28 a 33 anos } & 14 & 29,2 \\ \text { Mais de } 33 \text { anos } & 27 & 56,3\end{array}$


Tempo de Serviço

\begin{tabular}{lcrr} 
& De 1 a 10 anos & 12 & 25,0 \\
& De 11 a 20 anos & 13 & 27,1 \\
& De 21 a 30 anos & 20 & 41,7 \\
Grau de Instrução & Mais de 30 anos & 3 & 6,3 \\
& & \\
& Ensino Superior & 28 & 58,3 \\
Total & Mespecialização & 12 & 25,0 \\
& & 8 & 16,7 \\
\hline Tonte: & 48 & 100 \\
\hline
\end{tabular}

Fonte: Dados da pesquisa.

Porém, além da experiência, julga-se relevante, também, verificar a formação acadêmica apresentada pelos respondentes. O que chama a atenção é que nenhum respondente possui apenas o Ensino Médio: 58,33\% têm nível superior, 25\% têm especialização e 16,67\%, mestrado. Estes dados, somados ao tempo de serviço e à idade dos Analistas e Auditores das ICFEx pode representar o elevado conhecimento existente em relação às funções exercidas, demonstrando possível alta qualidade no nível das respostas obtidas.

Tabela 2 - Respostas aos Itens do Questionário

\begin{tabular}{|c|c|c|c|c|c|c|c|c|c|c|}
\hline \multirow[t]{2}{*}{ Questão } & \multicolumn{2}{|c|}{$\begin{array}{c}\text { DESCONHEÇO } \\
\text { O ASSUNTO }\end{array}$} & \multicolumn{2}{|c|}{$\begin{array}{c}\text { DISCORDO } \\
\text { FORTEMENTE }\end{array}$} & \multicolumn{2}{|c|}{$\begin{array}{c}\text { MAIS } \\
\text { DISCORDO } \\
\text { DO QUE } \\
\text { CONCORDO }\end{array}$} & \multicolumn{2}{|c|}{$\begin{array}{c}\text { MAIS } \\
\text { CONCORDO } \\
\text { DO QUE } \\
\text { DISCORDO }\end{array}$} & \multicolumn{2}{|c|}{$\begin{array}{c}\text { CONCORDO } \\
\text { FORTEMENTE }\end{array}$} \\
\hline & $N$ & $\%$ & $n$ & $\%$ & $n$ & $\%$ & $N$ & $\%$ & $n$ & $\%$ \\
\hline Q1 & 2 & 4,2 & 0 & 0 & 8 & 16,7 & 16 & 33,3 & 22 & 45,8 \\
\hline Q2 & 1 & 2,1 & 0 & 0 & 10 & 20,8 & 18 & 37,5 & 19 & 39,6 \\
\hline Q3 & 2 & 4,2 & 1 & 2,1 & 8 & 16,7 & 16 & 33,3 & 21 & 43,8 \\
\hline Q4 & 4 & 8,3 & 0 & 0 & 11 & 22,9 & 12 & 25,0 & 21 & 43,8 \\
\hline Q5 & 2 & 4,2 & 0 & 0 & 14 & 29,2 & 11 & 22,9 & 21 & 43,8 \\
\hline Q6 & 2 & 4,2 & 0 & 0 & 8 & 16,7 & 15 & 31,3 & 23 & 47,9 \\
\hline Q7 & 2 & 4,2 & 0 & 0 & 10 & 20,8 & 13 & 27,1 & 23 & 47,9 \\
\hline Q8 & 2 & 4,2 & 1 & 2,1 & 13 & 27,1 & 12 & 25,0 & 20 & 41,7 \\
\hline Q9 & 2 & 4,2 & 0 & 0 & 14 & 29,3 & 13 & 27,1 & 19 & 39,6 \\
\hline Q10 & 2 & 4,2 & 1 & 2,1 & 7 & 14,6 & 17 & 35,4 & 21 & 43,8 \\
\hline
\end{tabular}

Fonte: Dados da pesquisa.

$\mathrm{Na}$ percepção geral das ICFEx, considerando todas as respostas, apenas $0,62 \%$ discordaram totalmente, e observa-se, também, baixo índice em relação ao desconhecimento do assunto, com 4,37\%. Mas o que pode se apresentar como uma confirmação da percepção positiva dos respondentes é o percentual de $43,75 \%$ das respostas concordo totalmente para as questões realizadas, as quais se mostram alinhadas com o processo de convergência, novas normas, apuração dos custos, melhor geração de informações e tomada de decisão.

De forma geral, considerando todas as perguntas e um total de 48 respondentes, obteve-se $43,75 \%$ das respostas como concordo totalmente para todas as questões realizadas. Passando a considerar todas as respostas obtidas para desconheço o assunto, em todas as questões realizadas houve, em média, $4,38 \%$ de ocorrência para esse tipo de resposta.

Já para as respostas discordo totalmente, a média foi de $0,63 \%$ de ocorrência. Este fato pode indicar, além de um baixíssimo índice, que a ICFEx, seus Auditores e Analistas 
concordam com o atual momento da Área Pública, da atualização da legislação e da necessidade de melhor apuração dos custos no Exército.

Pode-se entender, com base na percepção dos que analisam e auditam os dados lançados no SISCUSTOS que: as novas normas alteraram a forma dos servidores trabalharem; os Analistas e Auditores entenderam que as informações apoiam na decisão a ser tomada; a contabilidade de custos aplicada no Exército está alinhada com as novas normas contábeis; os dados que são lançados no SISCUSTOS estão de acordo com as novas normas em relação à contabilidade de custos; os Analistas e Auditores demonstram total crença na utilidade das informações que são lançadas no SISCUSTOS; os Analistas e Auditores acreditam na utilidade das informações que são lançadas no SISCUSTOS; os dados lançados podem ser utilizados por eles para poder controlar o desperdício de recursos públicos; os Analistas e Auditores apresentam crença nas informações que estão sendo geradas; o SISCUSTOS proporciona a obtenção de informações capazes de analisar o desempenho do órgão que o utiliza; e que as informações geradas sobre os custos são relevantes e úteis para decidir sobre sua continuidade.

Em relação às pesquisas que foram tomadas como base para este trabalho, pode-se verificar que a pesquisa de Diniz (2004) concluiu que a estrutura administrativa das prefeituras não teria condições de implantar um sistema de custos, e que os gestores municipais concordavam com os conceitos de custos que poderiam ser aplicados. Havia percepção da necessidade de uma legislação específica e que os gestores concordavam com a necessidade de uma administração pública mais gerencial, com a utilização de princípios de eficiência e economicidade.

Por sua vez, Xavier Júnior (2011) constatou, em sua pesquisa, que a maioria dos contadores acredita que as informações produzidas estão de acordo com as novas normas e que são relevantes para a tomada de decisão, também verificou que a maioria dos contadores concorda que as informações produzidas com a implantação da apuração de custos serão úteis.

O estudo de De Faria (2012) mostra que é grande a aplicabilidade da Contabilidade de Custos, e que o sistema de custos do Banco Central tem condições de apresentar informações sobre todas as atividades e processos da Instituição. Porém, verificou que as informações não são fidedignas, e que o sistema não está sendo utilizado para tomada de decisão.

Desta forma, foi verificado se as percepções apresentadas nos trabalhos anteriores são as mesmas obtidas no Exército Brasileiro.

\section{Considerações Finais}

O objetivo desta pesquisa foi verificar se o SISCUSTOS gera informações relevantes sobre a apuração de custos, e sob o ponto de vista da nova contabilidade pública, na percepção dos Auditores e Analistas das ICFEx foi identificado que sim. Em outras palavras, os Auditores e Analistas acreditam na relevância dos dados gerados pelo Sistema de Apuração de Custos do Exército Brasileiro, e que este está em consonância com a atualização das normas contábeis na área pública.

A pesquisa descreveu o processo da Nova Administração Pública implantada no Exército Brasileiro, pesquisou sobre a contabilidade de custos no Exército Brasileiro, levantou as informações que são geradas pelo SISCUSTOS, verificou quais decisões são tomadas com 
base nas informações geradas pelo SISCUSTOS, investigou se o SISCUSTOS se adéqua ao que foi proposto pelas normas de contabilidade pública, e se fornece subsídios à tomada de decisão, e estabeleceu relações com a literatura para confirmar quais as percepções que ocorrem nas ICFEx e quais são as novas percepções. Para isso, foi considerada a característica qualitativa da relevância, que é a informação capaz de fazer a diferença na tomada de decisão pelo usuário.

Conseguiu-se responder à questão apresentada (Qual a percepção dos Auditores e Analistas das ICFEx a respeito da relevância das informações geradas pelo SISCUSTOS, em face da nova contabilidade pública para o processo decisório?), buscando as respostas dos Auditores e Analistas das Inspetorias de Contabilidade e Finanças do Exército em relação às informações geradas pelo SISCUSTOS, em face da nova contabilidade pública.

Para as ICFEx, 45,83\% concordam totalmente que a legislação alterou a forma de trabalho em relação às informações que são geradas, e para 43,75\%, há total concordância que a contabilidade de custos aplicada no Exército está alinhada com as novas Normas Contábeis. Da mesma forma, para 43,75\% dos respondentes, há concordância total de que são úteis, no processo de tomada de decisão, os dados que são lançados no Sistema de Apuração de Custos - SISCUSTOS - e as informações geradas pelo SISCUSTOS.

Na percepção das ICFEX em 2014, com totalidade de concordância, o SISCUSTOS cria medidas e padrões de grande utilidade para a tomada de decisão, para 47,91\%; permite o controle dos desperdícios de recursos públicos, para 47,91\%; permite a comparação de custos entre unidades com mesmas peculiaridades, para 41,67\%; e proporciona a obtenção de informações capazes de analisar o desempenho do órgão que o utiliza, para 39,58\%. Além disso, há total concordância para $43,75 \%$ dos respondentes de que o conhecimento dos custos é útil para decidir sobre a sua continuidade ou não.

Os Auditores e Analistas no Exército concordaram, em sua maioria, com 77,08\% de concordância, considerando a concordância total mais os que mais concordam que discordam, de que "As informações que são produzidas atualmente pela contabilidade apoiam o processo de decisão das ICFEx".

Houve uma grande demonstração de crença na utilidade das informações que são lançadas no SISCUSTOS, pois $43,75 \%$ das respostas foram concordo totalmente, sendo a opção mais respondida e não havendo uma única resposta para discordo totalmente.

Foi verificado que, para $47,91 \%$, o sistema de custos torna possíveis as comparações e cria medidas e padrões de grande utilidade para a tomada de decisão.

A fidedignidade das informações geradas pode ser percebida pelas respostas de $41,67 \%$ dos respondentes, que revelaram crer totalmente ser possível a comparação dos custos entre Organizações Militares. Ademais, para 39,58\%, as informações servem de base para analisar o desempenho do órgão que as utiliza e, ainda, para 79,16\% na soma de total concordância com mais concorda que discorda, os custos dos produtos e serviços públicos são úteis para decidir por sua continuidade ou não.

Dessa forma, pode-se considerar que, diferentemente das pesquisas que foram base para este trabalho realizado no Exército, a percepção das ICFEx é positiva para um acompanhamento das novas normas que seguem o processo da Nova Administração Pública. Também se pode considerar que há um uso da contabilidade de custos, que as informações geradas pelo SISCUSTOS são úteis e atendem as decisões que são tomadas, e que o SISCUSTOS se adéqua ao que foi proposto pelas normas de contabilidade pública. 
Este estudo apresenta as atuais pesquisas na área, também que a ferramenta gerencial desenvolvida pelo Exército Brasileiro pode contribuir à melhoria do desempenho organizacional, o qual possibilitará obter subsídios para o planejamento das atividades e para a tomada de decisões, podendo ser aplicadas para outros órgãos públicos, possibilitando que percebam o estágio alcançado pelo Exército Brasileiro e possam aplicar estas percepções no desenvolvimento de seus Sistemas de Custos.

Devem-se considerar as limitações da pesquisa, pois se considerou apenas as percepções dos Analistas e Auditores do Exército Brasileiro, e também que o PIPCP tem até 2022 para ser avaliado, o que pode ter influenciado nas conclusões desta e das pesquisas que foram referência.

Assim, em pesquisas futuras, sugere-se o aprofundamento de estudos na área de gestão pública, especificamente na abordagem da identificação dos principais fatores que impedem a implementação de um sistema de custo e resultado que melhor se enquadre na administração pública; e definição de um modelo de sistema de informação de custo e resultado para a administração pública.

\section{Referências}

ALMEIDA, Diogo; SANTOS, Marcos Aurélio Reis dos; COSTA, Antônio Fernando Branco. Aplicação do coeficiente alfa de cronbach nos resultados de um questionário para avaliação de desempenho da saúde pública. Anais do XXX Encontro nacional de Engenharia de Produção. São Carlos, 2010.

ALMEIDA, Kátia de; FERREIRA, Calebe da Costa; OLIVEIRA, Roberta de Souza; ALYRIO, Rovigati Danilo; SALLES, Murilo Barbosa. Análise da Evolução da Metodologia Utilizada nos Artigos Publicados na Revista Contabilidade \& Finanças, USP. Seminários em administração. 2009.

BABBIE, E. Métodos de pesquisas de survey. Belo Horizonte: UFMG, 2003.

\section{BENNET, Bennett R., KREBS G. Local Development Public-Private Partnerships Initiation in Britain and Germany Belhaven Press. London, NY, 1991.}

BRASIL. Lei $\mathbf{n}^{\mathbf{0}}$ 4.320. Brasília, 1964. Estatui Normas Gerais de Direito Financeiro para elaboração e controle dos orçamentos e balanços da União, dos Estados, dos Municípios e do Distrito Federal. Brasília, DF, Senado.

BRASIL. Lei Complementar n 101. Lei de Responsabilidade Fiscal. (LRF) Brasília, 2000.

BRASIL. Decreto lei no 200. Dispõe sobre a organização da Administração Federal, estabelece diretrizes para a Reforma Administrativa. Brasília, 1967.

BRASIL. Secretaria do Tesouro Nacional. Portaria $n^{0}$ 548, de 24 de setembro de 2015. Estabelece prazos-obrigatórios relativos à implantação dos Procedimentos Contábeis Patrimoniais na União, nos estados, no Distrito Federal e nos municípios brasileiros. Brasília, 
DF. 2015. Disponível em:

$<$ https://www.tesouro.fazenda.gov.br/documents/10180/390684/Portaria-STN-548-2015anexo-pipcp/331a2764-dc97-473a-82b0-deb3cdd2380f $>$. Acesso em 02 Jun. 2016.

BRASIL. Secretaria do Tesouro Nacional. Portaria $\mathbf{n}^{\mathbf{0}}$ 700, de 10 de dezembro de 2014. Aprova a $6^{a}$ edição do Manual de Contabilidade Aplicada ao Setor Público - MCASP, e dá outras providências. Brasília, DF. 2014. Disponível em: <

http://www.tesouro.fazenda.gov.br/documents/10180/456785/CPU_MCASP+6\%C2\%AA\%2 0edi\%C3\%A7\%C3\%A3o_Republ2/fa1 ee713-2fd3-4f51-8182-a542ce123773 >. Acesso em 24 Maio. 2016.

BRASIL. SISTEMAS DE INFORMAÇÕES DE CUSTOS NO GOVERNO FEDERAL: Orientações para o desenvolvimento e implantação de metodologias e sistemas de geração e emprego de informações de custos no Governo Federal. Consolidação dos trabalhos da Câmara Técnica da Qualidade do Gasto, instituída no âmbito do Comitê Técnico de Orçamento de que trata a Portaria SOF n. ${ }^{\circ}$ 68, de 21 de dezembro de 2007, da Secretaria de Orçamento Federal, e continuidade dos trabalhos realizados pela Comissão Interministerial instituída pela Portaria Interministerial n. ${ }^{\mathbf{9} 945}$, de 26 de outubro de 2005. Brasília, 2008.

BRESSER PEREIRA, Luiz Carlos. Ministério da Administração Federal e Reforma do Estado. Caderno 3 da Reforma do Estado. Brasília, DF, 1997.

COELHO, Cláudio Ulysses Ferreira. LINS, Luiz dos Santos. Teoria da contabilidade: abordagem contextual, histórica e gerencial. 1. ed. São Paulo: Atlas, 2010.

COSTA, Frederico Lustosa. 2008. Brasil: 200 anos de Estado; 200 anos de Administração Pública; 200 anos de reforma. Revista de Administração Pública, Rio de Janeiro, v. 42, n. 5, p. 829-874, out 2008.

CPC. Comitê de Pronunciamentos Contábeis. Pronunciamento conceitual básico. Estrutura conceitual para a elaboração e demonstração de relatório contábil-financeiro. Brasília, 2011.

CUNHA, Rafael Koifman Carneiro da; SILVA, César Augusto Tibúrcio. Análise da facilidade de leitura das demonstrações contábeis das empresas brasileiras: uma investigação do gerenciamento de impressões narrativas contábeis. Anais do Congresso USP - Contabilidade e Controladoria, 9, 2009, São Paulo, 2009.

DE FARIA, Adriana Moreira Bastos. Gestão de Custos e Orçamento Gerencial na Administração Pública Federal: O caso do Banco Central do Brasil. Dissertação (Mestrado em Administração). UFMG, 2012.

DINIZ, Josedilton Alves. Percepções de gestores e assessores contábeis da administração pública sobre aspectos do sistema de custos e resultados: uma análise em prefeituras 
municipais do Estado da Paraíba. Dissertação (Mestrado em Ciências Contábeis). UNB, 2004.

FARIA, Carlos Eduardo Pires. A implantação do sistema gerencial de custos (SISCUSTOS) desenvolvido pelo Exército Brasileiro: estudo de caso na $1^{\text {a }}$ Inspetoria de Contabilidade e Finanças do Exército. Dissertação (Mestrado em Ciências Contábeis). UERJ, 2010.

GIBBON, Artur Roberto de Oliveira; PORTO, Joyce Alves; CALDAS, Daniele Mendes; MACHADO, Debora Gomes. Aplicação do custeio baseado em atividade (ABC) no setor governamental: um estudo de caso aplicado ao almoxarifado da câmara municipal de Rio Grande/RS. In. Anais do XV Congresso Brasileiro de Custos. Curitiba, PR, Brasil, 12 a 14 de novembro de 2008.

GIL, Antônio Carlos. Como elaborar projetos de pesquisa. 4. ed. São Paulo: Atlas, 2008.

HODGES, R.; WRIGHT, M.; KEASEY, K. Corporate Governance in the Public Services: Concepts and Issues. Public Money \& Management, v. 16, n. 2, p. 7-13, apr./jun., 1996.

HYNDMAN, N; MCDONNELL, P. Governance and charities: An exploration of key themes and the development of a research agenda. Financial Accountability Management. v. 25, n. 1, p. 5-31. 1991.

IFAC - INTERNATIONAL FEDERATION OF ACCOUNTANTS. Perspectives on Cost Accounting for Government. New York: IFAC, Set. 2000. (IFAC Public Sector Committee - Study 12). Disponível em: < http://www.ifac.org/sites/default/files/publications/files/study12-perspectives-on.pdf.> Acesso em 24 de abril de 2011.

KOTHARI, S. P. Capital market research in accounting. Journal of Accounting and Economics, Rochester, v. 31, n. 1, p. 105-231, Sept. 2001.

LAKATOS, Eva Maria; MARCONI, Marina de Andrade. Fundamentos de Metodologia Científica. $7^{\mathrm{a}}$ ed. São Paulo: Atlas, 2010.

LUZ, Hederaldo Ricardo Inglês da; REIS, Dálcio Roberto dos. SISCUSTOS como ferramenta na medição de custos logísticos em um Batalhão de Suprimento do Exército. Anais do V Congresso Virtual Brasileiro de Administração, 2008.

MACHADO, Nelson; HOLANDA, Victor Branco de. Diretrizes e modelo conceitual de custos para o setor público a partir da experiência no governo federal do Brasil. Revista de Administração Pública, Rio de Janeiro, v. 44, n. 4, p. 791-820, ago/2010.

MACHADO, Nelson et al. (Org.). GBRSP - Gestão baseada em resultado no setor público: uma abordagem didática para implementação em prefeituras, câmaras municipais, autarquias, fundações e unidades organizacionais. São Paulo: Atlas, 2012. 267 p. 
MATIAS-PEREIRA, J. Finanças públicas: a política orçamentária no Brasil. $3^{\mathrm{a}}$ ed. São Paulo: Atlas, 2006.

MELLO, Gilmar Ribeiro de. Governança corporativa no setor público federal brasileiro. 2006. 119 f. Faculdade de Economia, Administração e Contabilidade, Dissertação (Mestrado em Ciências Contábeis). Universidade de São Paulo, São Paulo, 2006.

MENESES JÚNIOR, Raimundo Avilton. Análise do novo modelo de gestão do custeio dos serviços públicos estaduais no governo do Ceará. MAAP GESTÃO. Universidade Federal do Estado do Ceará. Dissertação (Mestrado em Economia). UFCE, 2013.

OLIVEIRA, Robson Ramos; SILVA, Aline Bernardino da; NASCIMENTO, Viviane Miranda Silva do. Custos em organizações públicas: estado da arte da produção científica. Seminários em administração. 2013.

PASSOS, Luís Henrique Santos. O impacto das normas brasileiras de contabilidade aplicadas ao Setor Público: Cenário atual e perspectivas na Administração Pública Federal. Revista de Administração de Roraima, Ed. 2, v. 1, p 110-135, $1^{\circ}$ sem. 2012.

RAUPP, Fabiano Maury; BEUREN, Ilse Maria. Metodologia da pesquisa aplicável às ciências sociais. In: BEUREN, Ilse Maria (org.). Como elaborar trabalhos monográficos em contabilidade: teoria e prática. 3 ed. São Paulo: Atlas, 2006. p. 76-97.

SEF. Secretaria de Economia e Finanças. Portaria $\mathbf{n}^{0}$ 050, de 10 de fevereiro de 2003. Regulamento das Inspetorias de Contabilidade e Finanças do Exército. Disponível em: $<$ http://www.sef.eb.mil.br/2ICFEx/Legislacao/LegMil/Estatuto/R29.htm $>$ Acesso em 22 jul. 2013.

SEF. Portaria $\mathbf{n}^{\mathbf{0}}$ 015, de 16 de janeiro de 2004. Regulamento da Secretaria de Economia e Finanças do Exército. Disponível em: < $\underline{\text { http://www.sef.eb.mil.br/2ICFEx/Legislacao }>\text { Acesso }}$ em 23 jul. 2013.

SEF. Portaria $\mathbf{n}^{\circ}$ 932, de 19 de dezembro de 2007. Normas para funcionamento do Sistema Gerencial de Custos do Exército. Disponível em:

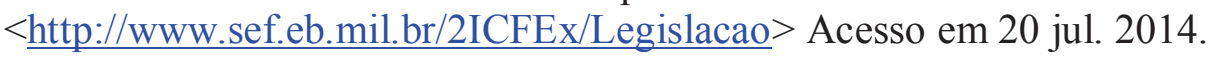

SLOMSKI, Valmor. Controladoria e Governança na Gestão Públicas. 1. Ed. 2005. $3^{\mathrm{a}}$ reimp. São Paulo: Atlas, 2005.

SLOMSKI, Valmor; CAMARGO, Guilherme Bueno de; AMARAL FILHO, Antônio Carlos Cintra do Amaral. Apuração do resultado econômico da Procuradoria Geral do Município de São Paulo. Anais XXXII Encontro da ANPAD. Rio de Janeiro, 2008.

SOF - SECRETARIA DE ORÇAMENTO FEDERAL - Sistemas de Informações de Custos no Governo Federal - Orientações para o desenvolvimento e implantação de 
metodologias e sistemas de geração e emprego de informações de custos no governo federal. Brasília-DF, Setembro/2008.

SOUZA, Domingos Carvalho de. A utilização da informação contábil na atividade pecuária do estado do Rio Grande do Norte: um enfoque nos demonstrativos gerados para tomada de decisão. 2004. Programa Multiinstitucional e Inter-Regional de PósGraduação em Ciências Contábeis. Dissertação (Mestrado em Ciências Contábeis). UnB, UFPB e UFRN, 2004.

STREINER, D. L. Being inconsistent about consistency: when coefficient alpha does and doesn't matter. Journal of Personality Assessment, v. 80, p. 217-222. 2003.

XAVIER JÚNIOR, Antonio Erivando. Percepção de operadores da contabilidade quanto à relevância das mudanças introduzidas pela adoção das normas brasileiras de contabilidade aplicadas ao setor público: Um estudo em instituições vinculadas ao Ministério da Educação. Dissertação (Mestrado em Ciências Contábeis). UNB. 2011. 
